\title{
Competency of the Infantry Troops of the Nepalese Army in Disaster Response
}

\author{
Shrijan Bahadur Malla ${ }^{1}$, Shuichi Hasegawa ${ }^{2}$, Ranjan Kumar Dahal ${ }^{3}$ \\ 1. Faculty of Engineering, Graduate School of Engineering, Kagawa University, 2217-20 Hayashi-cho, Takamatsu, \\ Kagawa 761-0396, Japan. \\ 2. Department of Safety Systems Construction Engineering, Kagawa University, Takamatsu City, Japan. \\ 3. Central Department of Geology, Tribhuvan University, Kritipur, Nepal.
}

Received April 7, 2019

Accepted April 27, 2019

\begin{abstract}
Although the Nepalese Army's regular infantry troops are the tools of disaster response their competency at times becomes questionable. Their disaster response's soft skill knowledge, technical skill knowledge and preparedness activities along with the perception of senior army officers have been analyzed. As per the result the disaster response competency of such troops needs improvements. The organization should focus on competency building activities. Besides, the perception of senior army officers is positive and convincing towards disaster response engagement.
\end{abstract}

Keywords: Nepalese Army, Infantry troops, Disaster response, Competency, Knowledge, Preparedness

\section{Introduction}

The risk of natural disaster arises when hazards interact with the physical, social, economic and environmental vulnerabilities and exposure to population (Selmi et al., 2015). Today the increased frequency of natural disaster has accumulated immense challenge to economic, social, health, cultural and environmental issues mostly in developing countries ${ }^{2}$.

Data show that in the world every year around 70,000 people loses their lives due to various natural disaster (UNISDR, 2015: Dahal et al., 2013). And most of them are from low and middle-income countries like Nepal. UNDP (2004) once reported that $11 \%$ of the people exposed to natural disaster hazards live in poor countries and those countries account more than $53 \%$ of the total disaster-related deaths.

In Nepal alone every year more than 500 people die due to various natural disasters since it is the $20^{\text {th }}$ most disaster prone country in the world (MOHA, 2018). It ranks $4^{\text {th }}$ vulnerable in terms of climate change and $11^{\text {th }}$ vulnerable in terms of earthquake (Nepal Disaster Report, 2017). Earthquake, flood, landslide, debris flow, avalanche, fire, and draught are amongst the disasters Nepal is always prone to (MOHA, 2015).
Disaster management is a complex cyclic process that has four phases i.e. mitigation, preparedness, response and recovery (Smet et al, 2015). Coming to this age although the disaster scientists have chiefly emphasized on mitigation process to reduce societal vulnerabilities to prevent disasters from occurrence the mitigation efforts only cannot prevent all disasters from occurrence hence requires preparedness activities to be ready for effective response(Lindell \& Perry, 1992).

Indeed, despite good mitigation and preparedness effort disaster always occurs that renders a response to be critical to reduce casualty and economic losses and to prevent the situation from further escalation (Wildavsky, 1988; Coppola, 2011; Wex et al, 2014). For poor countries like Nepal where investment in disaster mitigation is inadequate the need for an effective response mechanism is vital.

Today, in the worldly context, the militaries are somehow effective tools of disaster response mechanism. Higher magnitude and frequency of disasters overwhelm the capability of civilian government thus gives an opportunity to militaries to join hand in relief and rescue operations (Sahashi, 2015). Their specific assets (human and material), capacity to respond quickly on a larger scale and national political imperative makes them 
reliable tools of the governments to engage in the venture (Elizabeth, 2012; Hoff, 1999).

Especially in developing countries, the reliance on the military for disaster response is high since these countries lack effective and comprehensive civilian structures for disaster response (Malesic, 2015). In such situation, their regular infantry troops, along with specialized military units, become the part of their response mechanism (Raj, 2008; Hall \& Anita, 2010; Keen et al., 2011; Frank, 2005). But the effectiveness of such regular infantry's engagement at times becomes questionable.

Frederick C. Cunny (1991) argues that regular infantries are not trained for humanitarian roles. Their directives and training are inappropriate. Many scholars argue that military support is sought during disaster response because only of their logistic capability and human resource. Hofmann and Hudson (2009) write that the regular infantries' involvement in disaster response is inefficient, inappropriate, inadequate and expensive. Similarly, Weeks (2007) also suggests that in many occasions the military troops (regular infantry) were found ill-prepared to deal with the natural disaster since they hardly have any experience in the past and much military personnel find themselves experiencing myriad problems associated with a disaster situation.

Philippine mudslide of 2006, China Sichuan earthquake of 2008, Pakistan flood 2010, and Japan nuclear disaster of 2011 are some examples where the engagement of such regular infantry troops bore criticism (Hall \& Anita, 2010; Manish, 2018; Ajay \& Kundrat, 2011; Banyan, 2014; Martinez et al., 2015; Raja \& Arshad, 2015). Jake Hooker (2008) writes that the 'during the Sichuan earthquake the PLA soldiers (regular infantries) were mobilized quickly but couldn't do anything for the first 72 hours'. Later on, it was investigated that the disaster specialized PLA soldier was 5.6 times more effective than a regular infantry soldier (Li et al., 2009).

In Nepal as well the regular infantry troops of the Nepalese Army are the tools of natural disaster response (Manandhar et al., 2017; Thapa, 2016; Marshall \& Adkin, 2016; The Constitution of Nepal, 2015; Disaster Risk Reduction and Management Act, 2017). For security and disaster management their presence has been ensured in every district of the country. Today an infantry battalion has been deployed in every district of the country. 2017 Terai flood, 2015 Gorkha earthquake, 2014 Jure landslide, and 2008 Koshi flood are some examples where these troops have played significant role.
But in contrary to this urgency, disaster response preparedness of those regular infantry troops has remained in shadow. It is because the organization is moreover focused on strengthening its war-waging capability. The secondary mandate like disaster management has been facing chronic resource shortage (Poudel, 2016). In such a scenario full-fledged preparedness of such troops in disaster response is hardly attainable. And this reality was clearly evident during the response operations of Gorkha earthquake 2015. Various national and international after-action reports of Gorkha Earthquake have emphasized that there is a need to 'enhance search and rescue capability of Nepali Army'(MoHA, 2015; MoHA, 2016). They have also stated that the troops were less trained and less equipped for disaster response (Manandhar et al., 2017; Grunewald $\&$ Burlet, 2016).

Indeed, the effectiveness of response operation chiefly relies on the competency of the responders. Various disaster scientists have indicated that 'Knowledge' and 'preparedness activities' are the fundamental pillars of disaster response competency (Barsky et al., 2007; Gallardo et al., 2015). Harris et al. (2018) defines that the knowledge gives awareness of the given role(s) and task(s), that helps responder to work within the outlined framework, whereas preparedness renders him/her a platform to carry out effective, realistic and coordinated planning, reduces duplication of effort and increases overall effectiveness. In the void of these pillars, challenges persist in coordination, integration, and logistics, along with health and safety problems of the responder that may jeopardize the entire holistic effort of disaster response (Twigg \& Mosel, 2017).

Furthermore, disaster response knowledge consists of two categories i.e. 'Soft skill knowledge (SSK)' and 'Technical Skill Knowledge (TSK)' (Barelli et al., 2014). The SKK is non-technical, interpersonal and cognitive like principles, leadership, teamwork, and communication $^{42}$ whereas the TSK is procedural and systematic to function technical work like search and rescue, debris management, dead body management, casualty evacuation etc (Poul, 2018). And both the knowledge is prerequisite for the normal infantry troops since they have to carry out multiple functions during a disaster scenario. The Gorkha Earthquake is an example how these same troops carried out series of response operations like search and rescue, casualty evacuation, debris management, dead body management simultaneously (Barsky et al., 2007).

Similarly, training, exercise, and rehearsal are the cornerstone activities for building disaster response 
competency. Descy and Tessaring (2002) define that vocational training provides people with competence that is necessary and sufficient to perform a job. Ingrassia Pl et.al (2014) explains that all the professionals involved in disaster response should receive specific disaster-related training, exercise, and rehearsal regardless of their profession. As per Hsu et al. (2013) 'the quality, consistency, and frequency of disaster response training and exercise are acknowledged to notably impact selfperceived disaster preparedness of potential responders'. Jay Levinson (2008) writes in his article Military Involvement in Disaster Response that 'providing soldiers with disaster awareness training can only give better understanding when catastrophe arises'. He also adds that only technical units in military have skills with disaster response application, to field other units require training, drills and periodic refresher courses.

When it comes to competency building, the National Strategy for Disaster Risk Management 2009, the National Framework for Disaster Management 2013 and the Disaster Risk Reduction and Mitigation Act 2017 have also guided the Nepalese Army to carry out preparedness activities of its troops. Similarly, the Nepali Army Disaster Management Doctrine has also defined that training, exercise, and rehearsal are the regular tasks for the competency building.

In this backdrop, it is important that the knowledge and preparedness of normal infantry troops should be studied. But hardly this issue has garnered interest in the academic research field. Julia Hornyacsek (2018) admits that the 'disaster response competency of such regular infantry forces has hardly been studied'. In this regard, this research aims to study the disaster response competency of regular infantry troops of the Nepalese Army setting following research questions

(1) Whether the SKK and TSK of the regular infantry troops of the Nepalese Army adequate enough to carry out effective response operations?

(2) Did the preparedness activities i.e. training, exercise and rehearsal adequate of the general infantry troops of the Nepalese Army adequate enough to carry out effective disaster response operations?

(3) Is there any gap in the SKK and TSK, and preparedness of the regular infantry troops of the Nepalese Army?

(4) What is the perception of the senior army officers working at policy level about the
Nepalese Army's engagement in disaster management?

This last question is equally important because the perception of headquarters' officers ultimately helps to drive the Army's disaster response engagement since they play a crucial role to design plan, policies, and directives including the operational activities of the army. Ultimately this research paper will also be an aid to scholars interested to learn the competency of regular infantry troops of the Nepalese Army in disaster response.

\section{Methodology}

\subsection{Overview}

The research emphasized both qualitative and quantitative approach in the data collection and analysis. During survey qualitative interviews with various government officials, subject matter experts, retired and active the Nepalese Army officers have been carried out. Analysis of their experience, attitude, belief and thoughts, the study of national and international legal documents, binding and non-binding guidelines, plans and policies of the Nepalese Army have also been carried out.

The quantitative analysis was conducted through two sets of questionnaire surveys. One was for the infantry troops and other was for the senior army officers working at army headquarters level. The first survey was primarily focused on the study of the SSK, TSK and disaster response preparedness of the troops. Whereas, the second survey was focused studying the perception of high ranking officers about the army's engagement in disaster management. The questions were designed relatively cognitive to answer presuming that the Nepalese Army personnel are somehow acquainted with the disaster response venture through various pieces of training, educational programs, and operational engagements.

\subsection{Sample population and its analysis}

For quantitative survey altogether 270 active Nepalese Army personnel were selected as study participants. Amongst them, for first survey 245 personnel were randomly selected from 35 infantry battalions deployed in 35 districts. Mid-level officers below the rank of Major, Junior Commissioned Officers (JCOs) (also known as Warrant Officers) and other ranks (from the rank of soldier till the rank of Staff Sergeant) were the participants for the first survey. Their percentage was $19.7 \%, 20.6 \%$, and $59.7 \%$ respectively. Similarly, 25 officers above the rank of Lieutenant Colonel, working at 
various branches of army headquarters, were randomly selected for the second survey. The service year of all the study participants spanned from 2 to 36 years, with a mean value of 14.52 years and the standard deviation (SD) of 5.97 .

During the first survey, the junior officers working in the respective units, who have basic knowledge in disaster management, were selected as enumerators. They were asked to select the study participants who could understand and answer the questions. The survey was conducted in the presence of those enumerators themselves in an interview style for the clarity of the question. In average, it took 20-30 minutes for the participants to answer all the questions of the surveys.

\subsection{Research design}

In both surveys, closed-ended Self Administered Questions (SAQ) was asked to the responders as per the established methodology well described by Brancato et al. (2004), Ronan et al. (2010), Kuroiwa (1993), and Arya (1993).

During the first survey total of 22 questions configured into three categories were asked to the responders. First eight questions were asked about the SSK of disaster management. Fundamental issues like command control, civil-military relations, response priority, lead agency etc were the part of the questions. These questions were asked to the officers and JCOs since they are the field level commanders to lead disaster response operations.

Subsequently, in the second category, ten questions about disaster response's TSK were asked. Study of their perception of disaster response operations like search and rescue operations, medical assistance, debris management, dead body management etc was conducted. Study of the underlying technical issues was not part of the survey because it requires a separate scientific technical survey. Similarly, in the end, four questions related to disaster response preparedness activities i.e. training, exercise, rehearsal, and operational engagement were asked to the participants.

Likewise, the second survey was conducted amongst policy level officers. Altogether 7 questions were asked to them. How do they perceive about the engagement of the Nepal Army in disaster response operations was the scope of this survey. Fundamental issues of present engagement and its effect on Civil-Military Relations was the range of the study. 'How the policymakers want to drive this venture in future' was also the part survey.

Three types of closed-ended SAQs were designed for the surveys. First was of Likert Scale of five optional indicators of intensity rating scale i.e. (1) Strongly disagree (2) Disagree (3) Uncertain (4) Agree (5) Strongly agree. The second was of 'check all that apply' type questions and third was Dichotomous questions (Callegaro, 2014). During analysis, all the replies were re-coded into intensity rating scale.

\subsection{Method of analysis}

Fundamentally, the descriptive analysis method and inferential analysis method were adopted during research that helped to examine the relationship between the Nepal Army's disaster response competency building initiative and its effect on personnel competency. For the purpose, three key independent variables i.e. SSK, TSK, and disaster preparedness adaptation were considered as study factors. These variables were again analyzed on the basis of two dependent variables i.e. 'rank' (Officer, JCO and other ranks) and 'training' (Trained and Untrained troops). Whether these variables make any significant difference in the study participants' knowledge and preparedness or not was the aim of the analysis process. Similarly during the second survey prevailing perception of senior army officers on the engagement of the Nepalese Army in disaster response was analyzed.

Analytical tools such as bar graphs and comparison table, and tools of Linear Regression such as Pearson correlation matrix, model summary matrix, Anova, coefficients matrix were used during the analysis process. Through cross tabulation frequency distribution of the responses was studied. And the results were illustrated through bar graphs. For analysis the results of indicators of intensity rating scale were rephrased. For example, in an issue, if the respondent participant replied 'Strongly agree' then it was considered that he/she was well informed in that issue. Again through Linear Regression, the relationship between independent and dependent variables were examined. For example, the 'SSK' was examined amongst the Officers and JCOs through Cross tabulation and whether that relation is statistically significant or not was verified through Linear Regression. Results of bar graphs, model summary, Anova, and coefficients were illustrated in figures. Detail analysis was conducted using available commercial software and tools. 


\section{Result and Analysis}

\subsection{Soft Skill Knowledge (SSK)}

Eight fundamental questions were asked to the participant JCOs and Officers to study their SSK. The result of the survey indicated that more than $50 \%$ of the participants were not familiar with SSK issues (see Figure 1).

During the survey, only $35 \%$ of the participants strongly accepted that the army is the secondary responder. Rest $65 \%$ didn't recognize that the civilian mechanism is primarily responsible to save lives and property of the victims. They lacked to understand that the mobilization of the army is to substantiate the civilian effort. Similarly, more than $65 \%$ of the responders seemed confused about the issue that the army is the last resort for disaster response. Only $6 \%$ of the responders accepted that the army is the last resort for disaster response. This result illustrates that the participant officers and JCOs have a tendency of overestimating the role of the army in disaster response.

Likewise, only $40 \%$ of the participants were found to be familiar with the fact that the engagement of the army in disaster management will help to enhance CMR. Only about $30 \%$ of participants gave their consent that the role of disaster management is suitable for the army. In one hand overemphasizing the role of the army and in the other hand underestimating the significance of such engagement illustrates the confused state of knowledge of study participants.
But surprisingly in command control aspects, the responders were found quite knowledgeable. 70\% responder strongly agreed that for an effective response there should be joint command system comprised of civilian and military officials. Similarly, 63\% strongly agreed that the local authority should take the lead of response operation and $51 \%$ strongly believed that the MoHA is the leading agency for disaster response. But only $42 \%$ of participants were found aware that local government is the most responsible government for disaster management. Still, $58 \%$ of participants were unaware of this knowledge.

However, the overall responses of the participants showed that more than $50 \%$ of the participant JOCs and officers are still confused about SSK. Indeed such deficiency in junior leadership may create a dilemma in mobilization, command control and timely response.

\subsection{Technical Skill Knowledge (TSK)}

During the survey, ten questions were asked to the study participants to study their perception about fundamental technical tasks of disaster response. Although all the tasks are equally important for effective response only less than $30 \%$ of the participants recognized this fact. Around $70 \%$ of participants were found less aware of TSK (see Figure 2).

During the survey, only $50 \%$ of participants strongly agreed that the task of information collection and dissemination during disaster' and 'providing medical

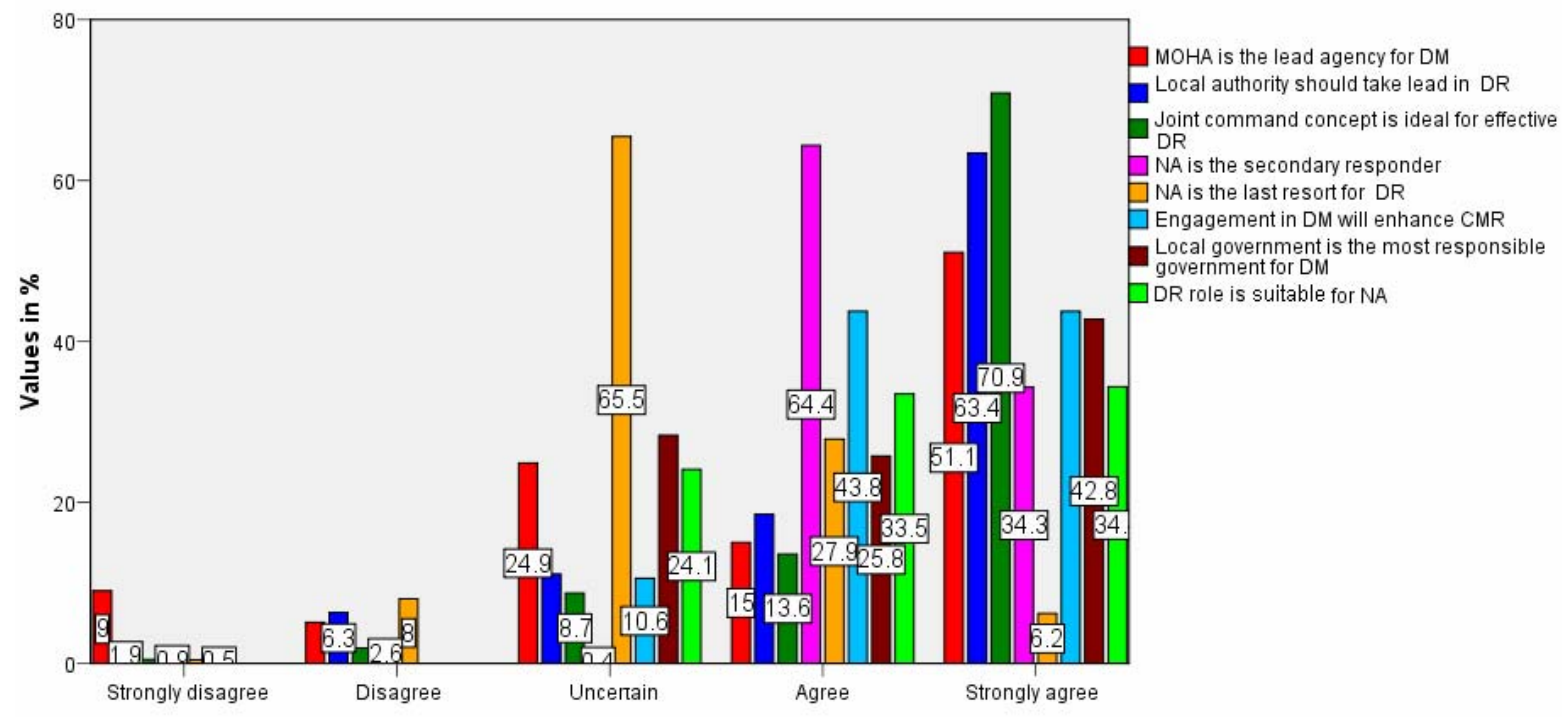

Figure 1. SSK of junior leadership (Officer and JCO) 


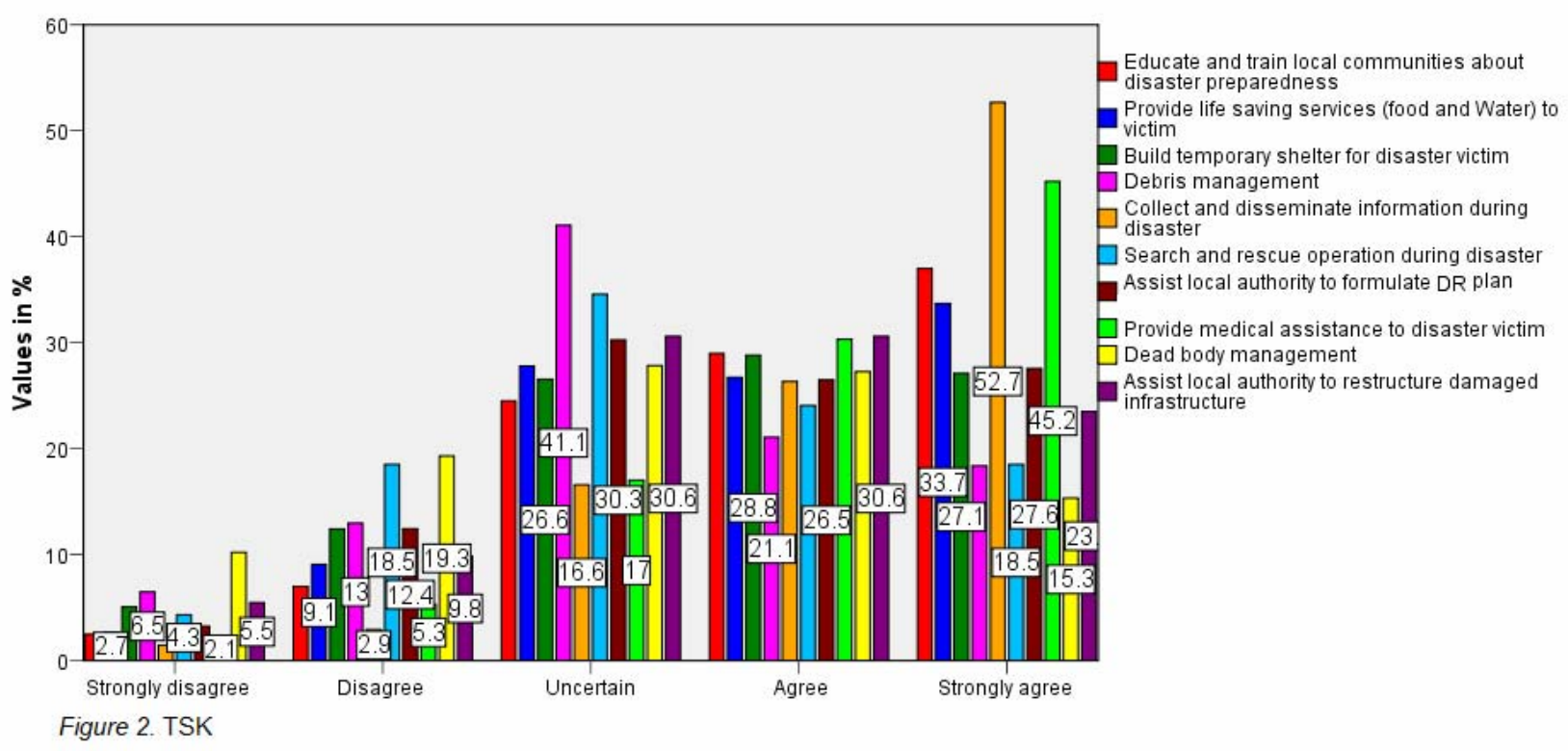

assistance to victims' are important for the army. But it is really surprising that more than $70 \%$ of the participants were not convinced that search and rescue, debris management; dead body management are important for the army during disaster response. Only less than $30 \%$ of participants choose them as the most significant. Indeed such confusion is counterproductive for an effective response because it creates negligence and lethargy amongst the responders resulting ignorance for preparedness. This result has indeed raised a question in the understanding level of study participants in TSK.

Similarly, $73 \%$ of respondents have failed to identify engineering assistance during post-disaster scenario as an important task for the army. Only $27 \%$ of participants strongly agreed that the army should construct temporary shelters for victims in the aftermath of the disaster and $23 \%$ of the participants considered assisting local authorities in restructuring damaged structures as most significant. Likewise, only $30 \%$ of the participants strongly believed that the task of providing life-saving services such as food and water to disaster victim should be conducted by the troops. This is again another surprising result derived from the survey. Similarly, $40 \%$ of responders identified that educating local people for disaster preparedness and assisting local authority to formulate disaster response plan is equally important for the Army.

An overall impression of the result suggested that nearly $70 \%$ of the respondents are still confused about prioritizing their operational tasks for disaster response. The level of their TSK is quite low.

\subsection{Disaster response preparedness activities}

Four questions were asked to the participants to study their involvement in disaster response preparedness activities. The survey showed that amongst total participants $57 \%$ have taken part in some sort of disaster management training in their career whereas $52 \%$ have participated in a disaster response exercise (see Figure 3). Indeed this is an encouraging finding that half of the participants have been acquainted with some kind of disaster preparedness activities. But in the part of the rehearsal, the response was low. Only $30 \%$ of participants replied that they use to rehearse on a regular basis at their unit. During survey weekly and monthly rehearsal was considered a regular rehearsal. Rest $70 \%$ of the respondents didn't have consistency in their rehearsal activities.

Similarly when asked about their engagement in disaster response operations $73 \%$ replied that they have been involved in some kind of rescue operations in the past (see Figure 3). If we look at the data still $16 \%$ of participants involved in disaster response operations were not trained in response operations. This result illustrates the Nepalese Army's trend of using untrained troops in disaster response operations. Similarly, in comparison to operational engagement, the trend of regular rehearsal is also low. 


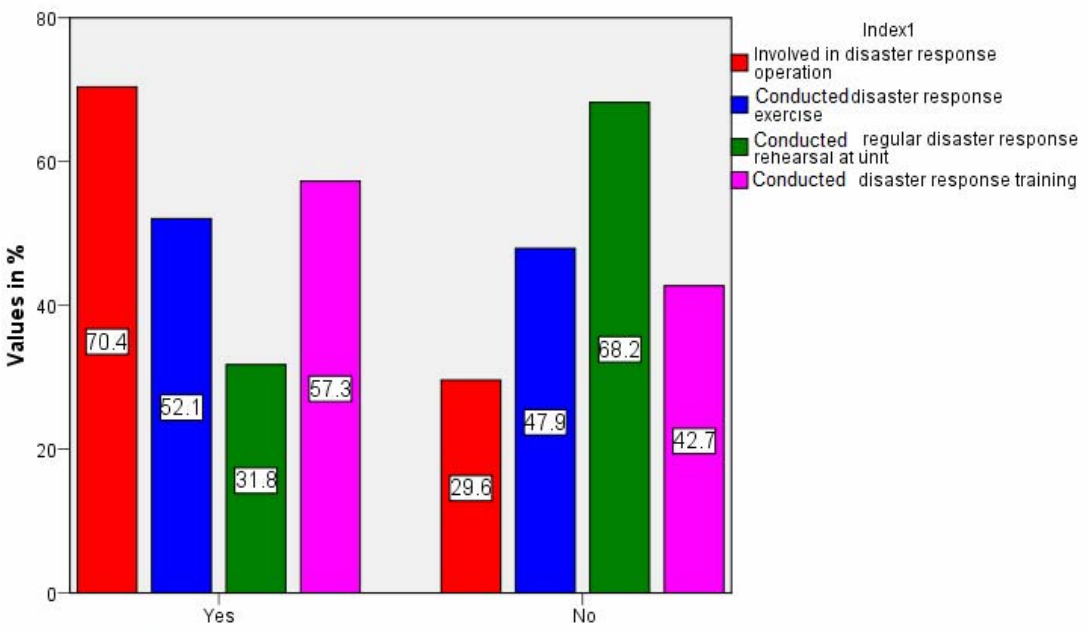

Figure 3. Disasrer response preparedness activities

\subsection{Effect of rank and training in the competency}

The competency of the study participants was also evaluated using correlation matrix Pearson Correlation result suggests that the participants who were knowledgeable in TSK were also knowledgeable in SSK and adopted in preparedness, whereas participants who were knowledgeable in SSK were also knowledgeable in TSK but not necessarily adopted in preparedness(see Table 1). And those who were adopted in preparedness were not necessarily bear SSK.

Table 1. Correlation matrix of competency

\begin{tabular}{|c|c|c|c|c|}
\hline Competency & & SSK & TSK & $\begin{array}{l}\text { Preparedness } \\
\text { activities }\end{array}$ \\
\hline \multirow[t]{2}{*}{ SKK } & $\begin{array}{l}\text { Pearson } \\
\text { Correlation }\end{array}$ & 1 & $.205^{*}$ & -.051 \\
\hline & Sig. (2-tailed) & & .041 & .566 \\
\hline \multirow[t]{2}{*}{ TSK } & $\begin{array}{l}\text { Pearson } \\
\text { Correlation }\end{array}$ & $.205^{*}$ & 1 & $-.193^{*}$ \\
\hline & Sig. (2-tailed) & .041 & & .041 \\
\hline \multirow[t]{2}{*}{$\begin{array}{l}\text { Preparedness } \\
\text { activities }\end{array}$} & $\begin{array}{l}\text { Pearson } \\
\text { Correlation }\end{array}$ & -.051 & $-.193^{*}$ & 1 \\
\hline & Sig. (2-tailed) & .566 & .041 & \\
\hline
\end{tabular}

* Correlation is significant at the 0.05 level (2-tailed).
To study whether the participants' training in disaster response makes any significant difference in their competency Linear Regression test was conducted. As per the equation derived $(\mathrm{F}(3,82)=11.384, \mathrm{p}<0.000)$ the disaster response training of participants is statistically significant to their response competency as a whole (see Table 2). But when compared individually, Coefficients test result illustrated that only the training has statistically significant relation with preparedness activities where the $\mathrm{p}$-value is less than $0.05(\mathrm{P}<0.000)$ and $\mathrm{t}$ value is 5.539 (see Table 3). That means the trained troops were more prepared than untrained troops, whereas with SKK and TSK training factor do not have any significant relation since $\mathrm{P}$ values are higher than 0.05 .

Similarly the rank factor also didn't make any statistically significant difference in the competency since the equation derived is $(\mathrm{F}(3,83)=2.222, \mathrm{p}>0.092)$ ( Table 4). And Coefficients result also illustrated that there was no statistical significance of rank with SSK, TSK, and preparedness individually since all $\mathrm{P}$ values are greater than 0.05 (see Table 5).

During analysis, it was found that in some issues of SSK only small percentage of Officers have better

\begin{tabular}{llllll}
\hline \multicolumn{5}{c}{ Table 2. Anova } \\
\hline Model & Sum of Squares & df & Mean Square & F & Sig. \\
\hline Regression & 6.045 & 3 & 2.015 & 11.384 & $.000^{\mathrm{a}}$ \\
Residual & 14.514 & 82 & .177 & & \\
Total & 20.558 & 85 & & & \\
\hline
\end{tabular}

a. Predictors: (Constant), Preparedness activities, SSK, TSK

b. Dependent Variable: Disaster management training 
Table 3. Coefficients

\begin{tabular}{|c|c|c|c|c|c|c|}
\hline \multirow[b]{2}{*}{ Mod } & & \multicolumn{2}{|c|}{ Unstandardized Coefficients } & \multirow{2}{*}{$\begin{array}{l}\text { Standardized Coefficients } \\
\text { Beta }\end{array}$} & \multirow[b]{2}{*}{$\mathrm{t}$} & \multirow[b]{2}{*}{ Sig. } \\
\hline & & $\mathrm{B}$ & Std. Error & & & \\
\hline \multirow[t]{4}{*}{1} & (Constant) & -.417 & .655 & & -.636 & .526 \\
\hline & SSK & .145 & .146 & .095 & .995 & .323 \\
\hline & TSK & .003 & .076 & .004 & .045 & .964 \\
\hline & Prep1 & .798 & .144 & .527 & 5.539 & .000 \\
\hline
\end{tabular}

a. Dependent Variable: Disaster management training

\begin{tabular}{lllllll}
\hline \multicolumn{7}{c}{ Table 4. Anova } \\
\hline Model & & Sum of Squares & df & Mean Square & F & Sig. \\
\hline 1 & Regression & 4.827 & 3 & 1.609 & 2.222 & $.092^{\text {a }}$ \\
& Residual & 60.092 & 83 & .724 & & \\
& Total & 64.920 & 86 & & & \\
\hline
\end{tabular}

a. Predictors: (Constant), Preparedness activities, SSK, TSK

b. Dependent Variable: Rank

Table 5. Coefficients

\begin{tabular}{|c|c|c|c|c|c|c|}
\hline \multirow[b]{2}{*}{ Model } & & \multicolumn{2}{|c|}{ Unstandardized Coefficients } & \multirow{2}{*}{$\begin{array}{l}\text { Standardized Coefficients } \\
\text { Beta }\end{array}$} & \multirow[b]{2}{*}{$\mathrm{t}$} & \multirow[b]{2}{*}{ Sig. } \\
\hline & & $\mathrm{B}$ & Std. Error & & & \\
\hline \multirow[t]{4}{*}{1} & (Constant) & -1.626 & 1.324 & & -1.228 & .223 \\
\hline & SSK & .557 & .295 & .206 & 1.888 & .062 \\
\hline & TSK & .169 & .153 & .122 & 1.101 & .274 \\
\hline & Prep1 & .238 & .291 & .089 & .819 & .415 \\
\hline
\end{tabular}

knowledge than JCOs. Otherwise there is no such difference in TSK of Officer, JCOs and other ranks (see Tables 6 \& 7). Similarly in preparedness as well, officers are marginally less trained, exercised and rehearsed than JOCs and other ranks (see Figure 4). But the involvement in response operations is almost equal. When it comes to training, besides preparedness there is no evidential difference in the percentage of trained and untrained troops in SSK and TSK (see Tables $6 \& 7$ and Figure 5).

\subsection{Prevailing engagement perception at the policy level}

Ten questions were asked to the participant officers from policy level to analyze their perception for the engagement of the Nepalese Army in disaster response. $84 \%$ of participants agreed that the army should be engaged more in disaster response in the future. But there also prevailed a huge gap $(75 \%)$ in the understanding that the government should invest more in establishing an effective civil defense mechanism for disaster response (see Figure 6). Even 32\% denied the fact that the Nepalese Army is filling the gap of lacked civil defense mechanism in the country.

Similarly, $84 \%$ of the participant agreed that in the federal system there should be dedicated disaster response units at each provincial level. Another $88 \%$ of respondents agreed that there should be specialized teams for search and rescue operations at each battalion level. Although this provision has been ingrained in the Nepalese Army's policy its robust implementation has not been achieved yet.

Many scholars have pointed out that over-reliance on the military for disaster response might garner threat to Civil-Military Relations (CMR) (Madiwale \& Virk, 2011). About $88 \%$ of the respondents agreed that there should be joint command control set up of Civilian and 
Table 6. SSK as per rank and training

\begin{tabular}{|c|c|c|c|c|}
\hline \multirow{2}{*}{ Description } & \multicolumn{2}{|c|}{ Rank } & \multicolumn{2}{|c|}{ Training } \\
\hline & JCO & Officers & Trained & Untrained \\
\hline Ministry of Home Affairs (MoHA) is the lead agency for disaster management & $77.10 \%$ & $54.30 \%$ & $61.40 \%$ & $72.30 \%$ \\
\hline Local authority should take lead in disaster response & $67.40 \%$ & $72.70 \%$ & $68.20 \%$ & $70.50 \%$ \\
\hline Joint command concept is ideal for effective disaster response & $68.20 \%$ & $74.40 \%$ & $73.20 \%$ & $65.10 \%$ \\
\hline Nepalese Army is the secondary responder for disaster response & $25 \%$ & $47.80 \%$ & $31.80 \%$ & $40.40 \%$ \\
\hline Nepal Army is the last resort for disaster response & $4.30 \%$ & $2.20 \%$ & $0.90 \%$ & $6.40 \%$ \\
\hline Engagement in disaster management will enhance Civil Military Relation (CMR) & $34.10 \%$ & $69.80 \%$ & $54.80 \%$ & $50 \%$ \\
\hline Local government is the most responsible government for disaster management & $44.40 \%$ & $48.70 \%$ & $42.50 \%$ & $52.40 \%$ \\
\hline Nepalese Army should play active role in disaster management & $29.90 \%$ & $36.40 \%$ & $25 \%$ & $30.20 \%$ \\
\hline
\end{tabular}

Table 7. TSK as per rank and training

\begin{tabular}{|c|c|c|c|c|c|}
\hline \multirow{2}{*}{ Description } & \multicolumn{3}{|c|}{ Rank } & \multicolumn{2}{|c|}{ Training } \\
\hline & OR & JCO & Officer & Trained & Untrained \\
\hline Educate and train local communities about disaster preparedness & $40 \%$ & $35.70 \%$ & $30.25 \%$ & $32.80 \%$ & $42 \%$ \\
\hline Provide life saving services like food and water to victim & $35.90 \%$ & $37.50 \%$ & $25 \%$ & $33.60 \%$ & $35.10 \%$ \\
\hline Build temporary shelter to disaster victim & $29.40 \%$ & $28.60 \%$ & $20 \%$ & $26.90 \%$ & $26.80 \%$ \\
\hline Debris management & $14.90 \%$ & $22.50 \%$ & $22.20 \%$ & $18.70 \%$ & $18.40 \%$ \\
\hline Collect and disseminate information during disaster & $50.40 \%$ & $48.80 \%$ & $62.80 \%$ & $50 \%$ & $56.50 \%$ \\
\hline Search and rescue operation during disaster & $18.50 \%$ & $19.50 \%$ & $17.90 \%$ & $22 \%$ & $13.30 \%$ \\
\hline Assist local authority to formulate disaster response plan & $27.70 \%$ & $19.50 \%$ & $35 \%$ & $27.50 \%$ & $27 \%$ \\
\hline Provide medical assistance to disaster victim & $53.30 \%$ & $35.90 \%$ & $34.10 \%$ & $44.30 \%$ & $47.40 \%$ \\
\hline Dead body management & $20.60 \%$ & $12 \%$ & $7 \%$ & $15.70 \%$ & $15 \%$ \\
\hline Assist local authority to restructure damaged infrastructure & $28.80 \%$ & $13.50 \%$ & $19 \%$ & $27.40 \%$ & $17.30 \%$ \\
\hline
\end{tabular}

Military authorities for effective response. And this is a promising gesture that Nepalese Army has accepted civilian control over response operations. To make the venture more effective $80 \%$ of participants believed that there should be an autonomous civilian entity for disaster response instead of giving full authority to MoHA. This is true since MoHA itself is an over-loaded agency with various responsibilities. Similarly, only $28 \%$ of officers agreed that disaster response training should be made compulsory for all ranks in the army.

The overall result of this survey gives an impression that around $70 \%$ of senior officer participants have position perception on the engagement of the Nepalese Army in disaster response.

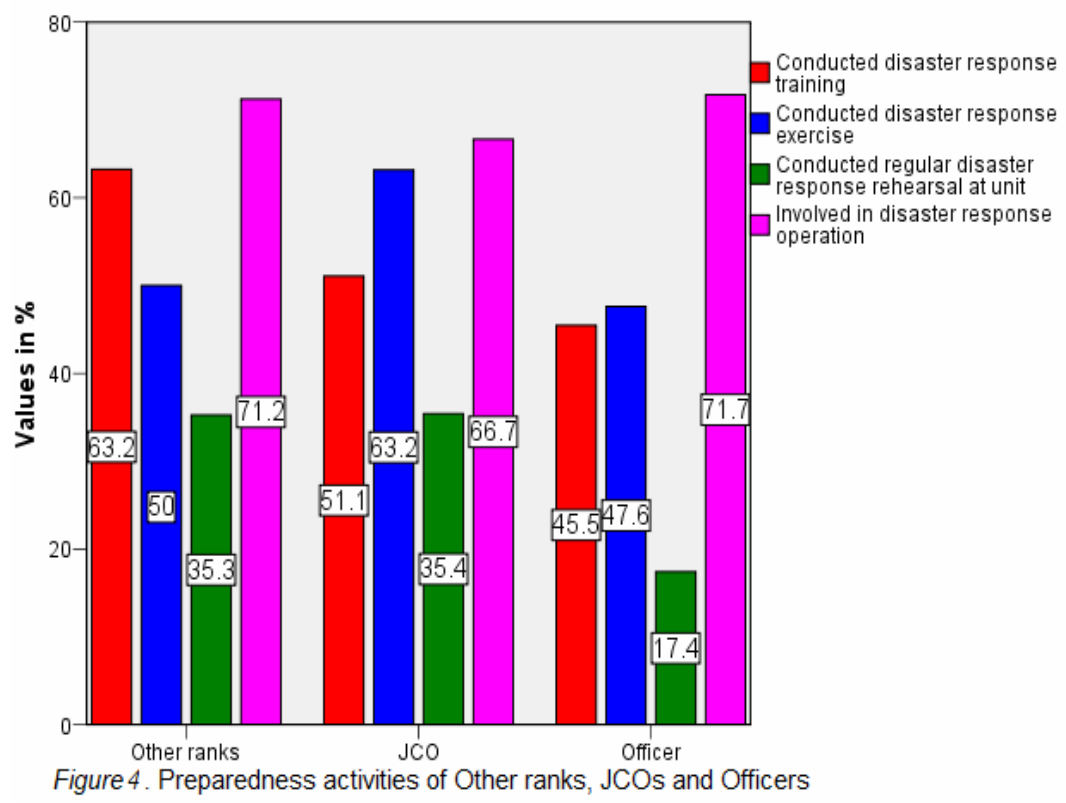




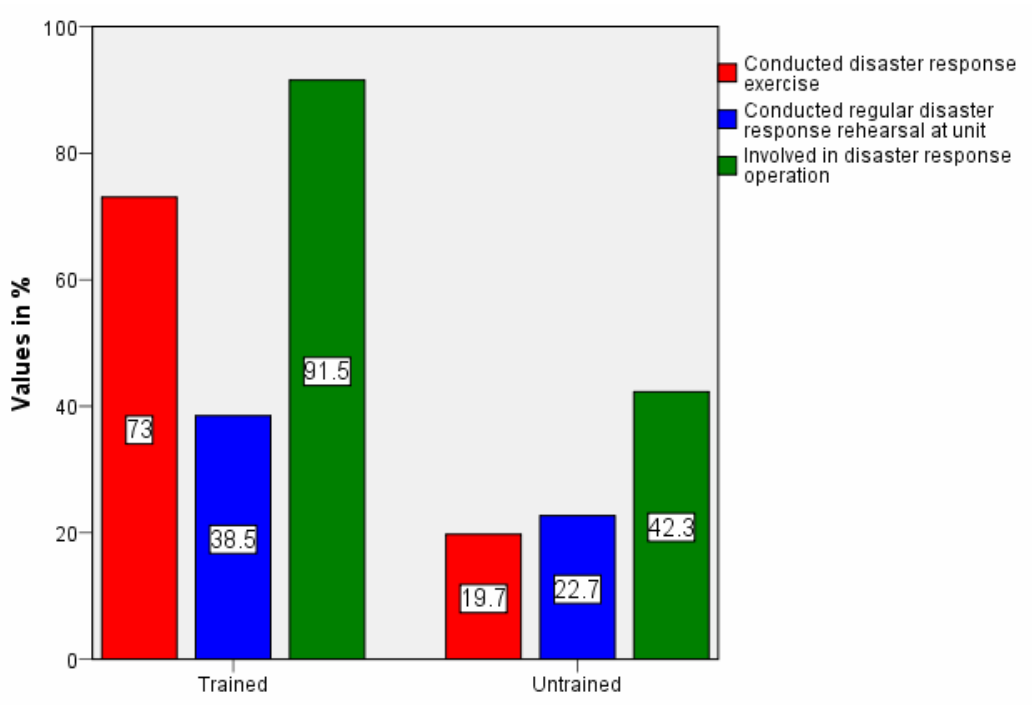

Figuer 5. Preparedness activities of trained and untrained troops

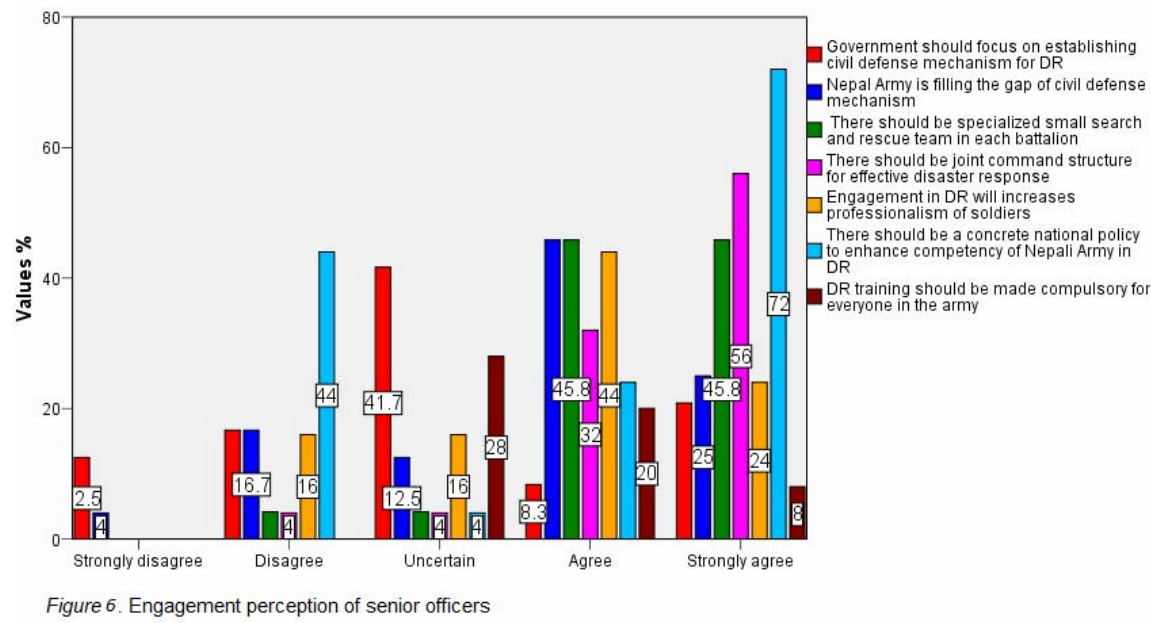

\section{Discussion}

This research has ultimately helped to understand the competency of the general infantry troops of the Nepalese Army in disaster response operations. Indeed, in the army, junior officers and JCOs are the key personalities. They are the one to lead disaster response operations in the field. But the result showed that the junior officers and JCOs have limited SKK. The issues of Civil-Military Relation, a priority of their engagement during a disaster, and the responsibilities of local government in disaster management are much important at their respective level. It is because at the local level they are the one to play interface between civilian authorities, civil societies and responding troops. They have to establish effective communication, coordination, and cooperation with those civilian bodies and civil communities at the time of preparedness and response. In the void of such knowledge, they can't drive the venture in an effective way.

Similarly, TSK was also found less promising amongst the participant infantry troops. This indicates that the general infantry of the Nepalese Army has confusions on their precise disaster response tasks. Only $30 \%$ of the participants strongly believed that search and rescue, debris management, dead body management, constructing temporary shelters for victims are important for the disaster response (MoHA, 2016). Such lacking will garner negligence and lethargy during preparedness that will ultimately hamper the response operations during a disaster. 
In the aspect of training, more than $50 \%$ of the participants were found participated in some kind of disaster-related training and exercise in their career. It is true that following the essence of national policies and guidelines (MoHA, 2017; Nepalese Army, 2017) the organization has credibly invested to train its infantry troops in disaster response training like Collapsed Structure Search and Rescue Training, Medical First Responders Training, Dead Body Management Training, Deep Water Rescue Training, and Sphere Training (Nepalese Army, 2017). But the result of SKK and TSK doesn't warrant qualitatively conduct of such training. The understandings of trained participants are low in many fundamental issues. And there is not much difference amongst trained troops' and untrained troops' responses. Surprising only $22 \%$ of the trained participants replied that Search and Rescue is the most suitable tasks for them for disaster response. This sort of gap clearly indicates the need for better orientation of the infantry troops in disaster response venture. Further research is suggested to investigate in-depth issues of this aspect.

Similarly, the result also revealed that the regular disaster response rehearsal is lacking in the regular infantry troops of the Nepalese Army. Margaret O'Leary (2004) states that 'the rehearsal is amongst the five core processes of disaster response preparedness that improves responders' future performance'. It doesn't only help to test the ability but also helps to enhance muscle memory. Regular counseling of the troops, practicing drills, tabletop exercise, and mock exercise are some examples of rehearsal activities. But their regularity is not consistency in the army. Only $30 \%$ of the responders replied that their units carry out such activities regularly.

Indeed the revealed result of the level of knowledge and preparedness has raised a question on the disaster response effectiveness of the regular infantry troops of the army. Levinson (2008) writes that the militaries only have logistics and human resource for disaster response. Hardly the ordinary troops are competent. And the tendency of engagement also reveals that disaster untrained troops are also the parts of disaster response operations. During the survey, around $20 \%$ of participants replied that they were untrained though they were engaged in some sort of response operations. This tendency also raises a question in the effectiveness of response operations.

During correlation analysis also it was found that who were knowledgeable were better prepared since they have a significant correlation. In that sense also quality training and regular rehearsal are indispensable for effective preparedness of the troops.

But during research hesitation was found amongst senior officers to make disaster response training compulsory for regular infantries despite their claim that the disaster response competency of such troops should be enhanced. Such tendency will not help the organization to achieve its aim.

Similarly, their disagreement in the need of an effective civilian response mechanism for disaster also generates a question that "whether they want to militarize the disaster response venture in Nepal'. Indeed such feelings contradict the international principle of disaster management, which warrants civilian supremacy for the venture (Miller et al., 2008). Such feeling may cause friction amongst civilian and military leadership in the long run.

However, the overall result of this research has illustrated that the knowledge base competency and preparedness of the general infantry troops of the Nepalese Army has limitations. Nevertheless, less number of samples populations and exclusion of detail study of disaster response training curriculum of the Nepalese Army are some limitation of this study. Despite such limitation whatever result has been derived from the study is definitely useful for other scholars who intend to learn about the competency of general infantry troops of the Nepalese army in disaster response.

\section{Conclusion}

There is no doubt that the Nepalese Army is amongst the key responding tools of the Nepalese government to respond to natural disaster. But the knowledge-based disaster response competency and preparedness of the general infantry troops of the Nepalese Army has remained deficit. Although disaster response training facility is satisfactory in the army the prevalent unawareness amongst troops in disaster management fundamental issues raises the question in the quality of those training programs. But in other hands at the policy level, the environment is aspiring. A better result can be expected in the future.

For preparedness, regular rehearsal of the troops is the missing part of the organization. Such a trend makes troops lethargic during a response operation. Also, the contradiction amongst senior officers in making disaster response training compulsory for all troops is also a hurdle to some extent for enhancing disaster response capability of the Nepalese Army. 
Definitely due to legal mandates the Nepalese Army has larger obligation to respond effectively during a disaster in the country and for that the maintenance of the competency of its troops is mandatory. And towards achieving the aim this kind of research plays an eyeopening role for the concerned authority.

\section{Acknowledgements}

This research has been conducted with the extensive support from the officials and staffs of Himalayan Conservation Group, Nepal and the Nepalese Army. The support from the active and retired senior army officers is very much acknowledged. Similarly, the officials from government authorities who rendered their guidance on policy matters are also note worthy of recognition for the success of this research paper.

\section{References}

A. A. Selmi, S. Egawa, H. Sasaki, et al., The Sendai Framework for Disaster Risk reduction: Renewing the Global Commitment to People's Resilience, Health, and Well Being, in Int J. Disaster Risk Sci. 6 (2015), pp.164-176.

UNISDR, Sendai framework for Disaster Risk Reduction 2015 2030 (2015).

R. K . Dahal, G. Tuladhar, R. Yatabe, et al., Knowledge of Disaster Risk Reduction among School Students in Nepal. Geomatic, in Natural Hazard and Risk (2013).

MoHA, National Position Paper on Disaster Risk Reduction and Management Nepal, in AMCDRR 2018 (Ulaanbaatar, 2018)

Nepal Disaster Report, The Road to Sendai (Final Draft) (2017). MOHA, Nepal Disaster Report 2015 (2015).

H. D. Smet, B. Schreurs, J. Leysen, The Response of the Disaster Management Life Cycle Revisited Within the Context of "Disasters Out of Box", in Homeland Security \& Emergency Management, 12(2) (2015), pp. 319-350.

M. K. Lindell, R.W. Perry, Behavioral Foundations of Community Emergency Planning (Hemisphere Publishing Corporation, Washington, DC, 1992).

A. B. Wildavsky, Searching for Safety (Transaction Publishers, New Brunswick, 1998).

D. P. Coppala, Introduction to International Disaster Management (Elsevier Inc. Burlington, 2011).

F. Wex, G. Schryen, S. Feuerriegel,et al., Emergency Response in Natural Disaster Management: Allocation and Scheduling of Rescue Units, in European Journal of Operational Research 235 (2014), pp. 697-708.

R. Sahashi, Disaster Relief and Risk Reduction in East Asia: The Role of Japan-ASEAN Cooperation, in Navigation change: ASEAN-Japan Strategic Partnership in East Asia and in Global Governance (2015), p.132. http://jcie.org/researchpdfs/ASEANJapan/NavChange/8.pdf

F. Elizabeth, Future directions in Civil-Military responses to natural disasters, Conflict prevention in practice: from rhetoric to reality, in ACMC Paper (2012).
A. P. Hoff, An Analysis of Disaster Relief and Humanitarian Supply Chains (Master's Dissertation) (Cranfield University, Shrivenham, England, 1999).

M. Malesic, The Impact of Military Engagement in Disaster Management on Civil-Military Relations, in Current Sociology (2015).

A. Raj, Armed Forces in Disaster response: Role Reappraisal, in CLAWS Journal (2008), pp. 163-176.

R. A. Hall, C. Anita, Civil Military Relations in Disaster Rescue and Relief Activities: Response to the Mudslide in Southern Leyte, Philippines, in South African Journal of Military Studies, 38 (2010).

P. K. Keen, F. P. V. Neto, C.W. Nolan, et al., Relationships Matter: Humanitarian Assistance and Disaster Relief in Haiti. JIIM Challenges in the Geographic Combatant Commands, in Newsletter (2011,11-23), pp.129-139.

J. Frank, A Neutral's perspective: The Role of Austrian Armed Forces in Homeland Security, in The Quarterly Journal (2005), pp.97-120.

F. C. Cuny, Dilemmas of Military involvement in Humanitarian relief, in Soldiers, Peacekeepers, and Disasters (St. Martin's Press, New York, 1991), pp. 52-81.

C. A. Hofmann, L. Hudson, Military responses to natural disaster: Last resort or inevitable trend, in British Red Cross (2009)

M. R. Weeks, Organizing for disasters: Lessons from the military, in Business Horizons 50(6) (2007), pp. 479-489.

M. Thapa, Out of Barracks: Civil - Military Relations in Disaster Management, A Case Study of Nepalese Army's Humanitarian Response during 2015 Earthquake in Nepal (University for Peace, San Jose, 2016).

M. Ajay, V. Kundrat, Civil-Military relations in Natural Disaster: a Case Study of the 2010 Pakistan floods, in International Review of the Red Cross 93(884) (2011).

Banyan, The 2011 Earthquake, Tsunami, and Nuclear Accident in Japan: Coordinating the U.S. Government Response, in A Banyan Analytics Case Study (2014).

G. Martinez, J. Flint, K. Sutton, Civil-Military-Police Coordination in Disaster Management, Perspectives from South East Asian Countries (Humanitarian Advisory Group, 2015)

S. Raja, A. Arshad, Armed Forces and Disaster Management, in American Journal of Social Science 1(3) (American Institute of Science, 2015),pp.152-157.

J. Hooker, Quake Revealed Deficiencies of China's Military, in The New York Times (2 July, 2008).

Y. Li, P. Huang, X. Sun, An analysis of the legal basis of PLA's participation in earthquake rescue operations, in Journal of the Institute of Disaster Prevention Science and Technology 1(2) (2009), pp. 117-120.

M. D. Manandhar, G. Varughese, A. M. Howitt, et al., Disaster Preparedness and Response During Political Transition in Nepal: Assessing Civil and Military Roles in the Aftermath of the 2015 Earthquakes, in The Asia Foundation (2017), pp. 5-6.

A. R. C. Marshall, R. Adkin, Nepalese army gets image boost from quake relief work, in Reuters (2015).

The Constitution of Nepal, Part 28, Article 267 (2015), p.197.

Disaster Risk Reduction and Management Act, Part 8, Article 18 (2017), pp. 24-26.

K. Poudel, Nepal Army by People's Side, in New Spotlight News Magazine 09(16) (March, 2016). 